\title{
A Novel Measurement Method for Coal Thermoplasticity: Permeation Distance
}

\author{
Yusuke DOHI, ${ }^{*}$ Kiyoshi FUKADA, Tetsuya YAMAMOTO, Takashi MATSUI, Hiroyuki SUMI and \\ Izumi SHIMOYAMA
}

Steel Research Laboratory, JFE Steel Corp., 1 Kokan-cho, Fukuyama, Hiroshima, 721-8510 Japan.

(Received on March 26, 2014; accepted on July 10, 2014)

\begin{abstract}
A novel measurement method for coal thermoplasticity was developed, where permeation distance of thermally plastic coal into glass beads layer placed on the coal sample was measured. The characteristic of this method is simulating the condition in a coke oven, especially void structure around the plastic layer by using glass beads and coking pressure by applying a load. In a standard condition, the coal sample is heated to $550^{\circ} \mathrm{C}$, and coal sample softens and permeates into the glass beads layer, then the permeation distance is measured after cooling the sample. The maximum permeation distance measured is roughly correlated with Gieseler fluidity, however large deviation is observed especially for high fluidity coals. Moreover, the deterioration of coke strength is observed in case that long permeation distance coal is used in a coal blend for cokemaking. This new measurement method clearly shows the difference in coking property of high fluidity coal as well as solving the problems in Gieseler plastometer method for evaluating high fluidity coals. By employing the permeation distance method, contribution to the production of high strength coke and effective usage of caking coal will be expected.
\end{abstract}

KEY WORDS: cokemaking; coal thermoplasticity; caking property; coking property; blending technique; coke strength; permeation distance.

\section{Introduction}

Caking properties are the essential parameters in coal blending techniques for cokemaking because those properties strongly influence the coke qualities. ${ }^{1-3)}$ In particular, Gieseler plastometer method and dilatometer test standardized by JIS M8801 have long been used for measuring the caking properties and finally controlling coke strength. ${ }^{4-6)}$ For example, Miyazu et al. shows that Gieseler maximum fluidity (MF) of coal blend should be more than $200 \mathrm{ddpm}$ to make high strength coke. ${ }^{4)}$ However, the effect of excessive MF on coke strength has not been clarified because high fluidity coal is thought to act as a binder in a coal blend to produce high strength coke while high fluidity coal produces highly-porous structure which leads fragile coke in case that the coal alone is carbonized. Nomura et al. shows that high strength coke needs a certain level of product of bulk density and "specific dilatation volume" which is defined as the volume of expanded coal per unit mass and measured by dilatometer test. ${ }^{6}$ ) Although high total dilatation (TD) coal is thought to have the ability to fill the initial gaps between packed coal particles and to enhance the coke strength, it is reported that large particles of high TD coal produces connected pores which acts as defects. ${ }^{7)}$ As just described, it has been pointed out that those conventional caking properties sometimes have not correlated with coke

* Corresponding author: E-mail: y-dohi@jfe-steel.co.jp DOI: http://dx.doi.org/10.2355/isijinternational.54.2484 strength.

The problems of the conventional caking properties are described below. One of the problems of Gieseler plastometer method is changing shear rate in coal sample during measurement. Viscosity of high fluidity coal is underestimated because thermally plastic coal behaves as pseudoplastic flow. ${ }^{8,9)}$ In addition, reliability of MF value in high fluidity coal is questioned because the phenomenon, in which the vicinity of the inner wall of a crucible becomes empty (Weissenberg effect), occurs and a stirring rod runs idle as shown in Fig. 1. ${ }^{8)}$ On the other hand, a problem of dilatometer test is considered that the measurement conditions, such as constraints of samples, gas and/or thermally

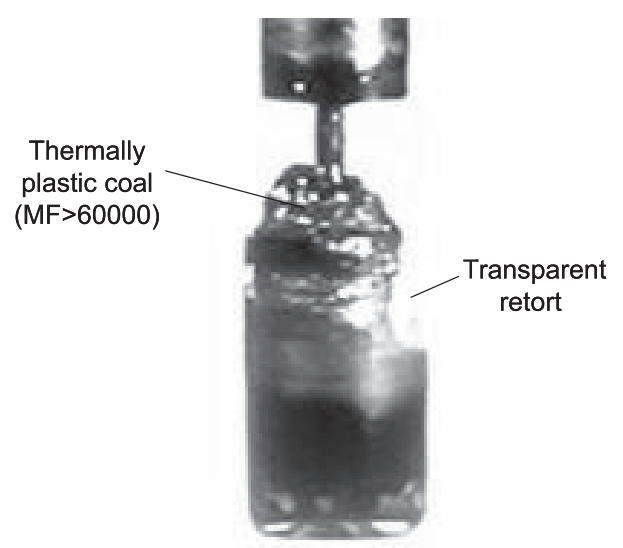

Fig. 1. Weissenberg effect observed in transparent Gieseler retort. ${ }^{8)}$ 


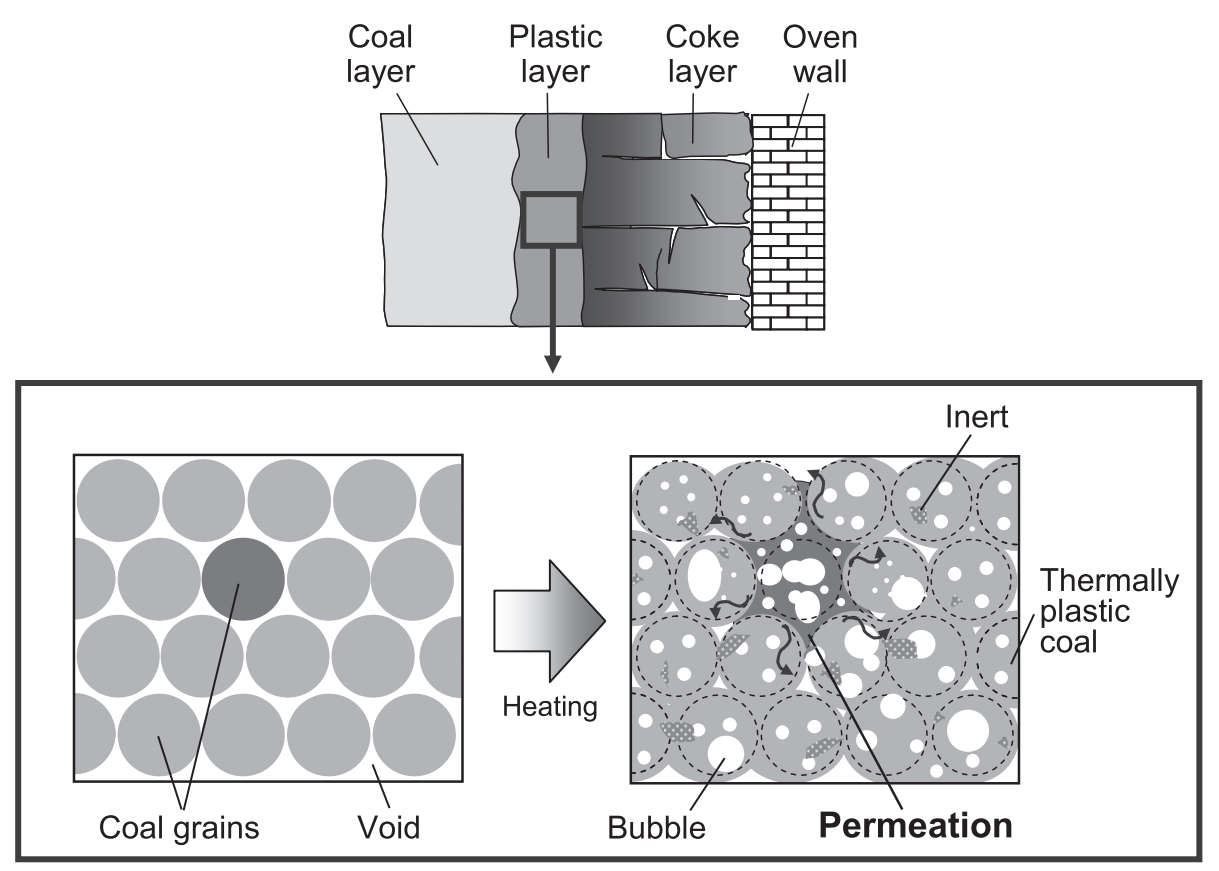

Fig. 2. Conceptual diagram of coal thermoplasticity in coke oven.

plastic sample paths etc., are not properly set with the objective of simulating the circumstances in a coke oven although those conditions drastically influence the dilatation behavior of coal sample. ${ }^{10,11)}$ In fact, the TD of commercial coal blend is quite bigger than the actual coal dilatation in coke oven.

The current status described above prompts us to develop a new measurement method of coal thermoplasticity. Our intention is to simulate the conditions around thermally plastic coal in a coke oven as shown in Fig. 2. Namely, it was considered that permeation of thermally plastic coal into void around itself and the coking pressure should be simulated. For that purpose, the measurement method of coal thermoplasticity, which includes placing glass beads layer to assume void structure on the coal sample, and applying pressure to the beads and coal sample to simulate the coking pressure during heating, was devised. In this paper, the detailed method of permeation distance measurement and its effect on coke qualities will be described.

\section{Fundamental Investigations of Coal Permeation}

\subsection{Experiments}

The characterization data of sample coal brands for measuring the permeation distance are shown in Table 1. In the table, the numbers after sample name mean the difference of lot. Measurements of Gieseler maximum fluidity (MF), total dilatation (TD), mean maximum reflectance of vitrinite ( $\overline{\mathrm{R}} \mathrm{o}$ ), and proximate analysis of coal samples were conducted according to JIS M8801, M8816, and M8812 respectively.

An apparatus for measuring the permeation distance is illustrated in Fig. 3. The apparatus basically consists of a electric furnace for heating the coal sample, a CCD camera (Keyence: XG-H500C), a image processing apparatus (Keyence: XG-7700) and a computer for measuring the permeation distance.

The experimental procedures are described below. $2.5 \mathrm{~g}$ of coal sample, which was crushed and sieved so that the particle diameter was not more than $2 \mathrm{~mm}$, was charged to the quartz crucible having the size of $20 \mathrm{~mm}$ in diameter and $100 \mathrm{~mm}$ in height. Then a weight (200 g) was dropped from above the sample five times with a fall distance of $20 \mathrm{~mm}$ to pack the sample, so that the thickness of the sample layer was around $10 \mathrm{~mm}$. Glass beads (Material: soda glass, Specific weight: 2.5 ) were arranged on the packed layer so as to achieve a thickness of over $50 \mathrm{~mm}$. On the glass beads layer, a quartz filter with a diameter of $19 \mathrm{~mm}$ and a thickness of $5 \mathrm{~mm}$ was arranged, and a quartz rod was placed on the filter. A weight was placed on the quartz rod so that the pressure was applied onto the glass beads and coal layers. The crucible was placed in the midst of electric furnace and was heated to $550^{\circ} \mathrm{C}$ at a heating rate of $3^{\circ} \mathrm{C} / \mathrm{min}$ under nitrogen. Upon heating, the thermally plastic coal permeated into the glass beads layer as shown in Fig. 4.

The standard experimental conditions for simulating the void structure and coking pressure are set as below. The glass beads size were set to $2.0 \mathrm{~mm}$ in consideration of mean diameter of general commercial coal blend. The weight was set to $1.6 \mathrm{~kg}$ so that the pressure levels were $50 \mathrm{kPa}$ according to the maximum wall pressure of coal blend whose volatile matter was $25 \mathrm{wt} \%$ d.a.f.. ${ }^{12)}$

For understanding the fundamental permeation behavior, the effect of the experimental conditions of glass beads size and pressure of weight on the measurement value was examined for CoalA2. The levels of glass beads size were set to $0.4,1.0$ and $2.0 \mathrm{~mm}$. The levels of pressure of weight were set to 25 and $50 \mathrm{kPa}$.

The permeation distance was measured in real time by image analysis technique with the image processing apparatus. The detailed analysis procedures are described below. Upon heating, the images of sample coal permeating into the glass beads layer were taken by the CCD camera via an observation window equipped on the electric furnace every 2 seconds. Those images were transferred to the image processing apparatus and computer. The coordinates of the boundary face between filter and glass beads layer (Boundary1), glass beads layer and permeating coal layer 
Table 1. Coal properties and measurement results.

\begin{tabular}{|c|c|c|c|c|c|c|c|}
\hline $\begin{array}{l}\text { Coal } \\
\text { brand }\end{array}$ & $\begin{array}{l}\overline{\mathrm{R}} 0 \\
(\%)\end{array}$ & $\begin{array}{c}\text { TI } \\
(\%)\end{array}$ & $\begin{array}{l}\text { Ash } \\
\text { (wt\% } \\
\text { d.b.) }\end{array}$ & $\begin{array}{c}\text { VM } \\
\text { (wt\% } \\
\text { d.b.) }\end{array}$ & $\begin{array}{c}\log M F \\
(\log / \\
\text { ddpm) }\end{array}$ & $\begin{array}{l}\text { TD } \\
(\%)\end{array}$ & $\begin{array}{c}\text { Maximum } \\
\text { permeation } \\
\text { distance } \\
(\mathrm{mm})\end{array}$ \\
\hline CoalA1 & 0.89 & 20.9 & 7.5 & 34.4 & 3.21 & 169 & 20.4 \\
\hline CoalA2 & 0.90 & 14.9 & 7.3 & 34.5 & 3.71 & 179 & 22.6 \\
\hline CoalB1 & 0.67 & 17.1 & 5.2 & 44.1 & 3.64 & 78 & 10.3 \\
\hline CoalB2 & 0.65 & 15.5 & 5.4 & 44.0 & 3.57 & 99 & 12.2 \\
\hline CoalC1 & 1.32 & 39.1 & 6.9 & 19.8 & 0.78 & 25 & 1.5 \\
\hline CoalC2 & 1.31 & 45.6 & 7.2 & 20.4 & 1.26 & 20 & 2.5 \\
\hline CoalC3 & 1.37 & 44.3 & 7.2 & 19.3 & 1.04 & 20 & 0.9 \\
\hline CoalD1 & 1.52 & 19.9 & 7.3 & 19.9 & 1.32 & 57 & 3.5 \\
\hline CoalE1 & 0.72 & 14.3 & 9.5 & 40.1 & 4.09 & 145 & 14.9 \\
\hline CoalE2 & 0.74 & 17.4 & 9.5 & 40.3 & 4.07 & 123 & 16.8 \\
\hline CoalF1 & 0.80 & 14.5 & 7.7 & 36.9 & 3.17 & 171 & 20.8 \\
\hline CoalG1 & 0.71 & 8.0 & 0.4 & 43.6 & 4.78 & 210 & 32.4 \\
\hline CoalH1 & 0.86 & 19.9 & 9.5 & 34.3 & 3.19 & 95 & 10.3 \\
\hline CoalI1 & 0.65 & 23.0 & 10.7 & 36.6 & 1.46 & 0 & 3.3 \\
\hline CoalJ1 & 0.78 & 14.6 & 9.0 & 36.6 & 2.10 & 48 & 7.6 \\
\hline CoalK1 & 0.84 & 8.7 & 6.0 & 36.4 & 3.50 & 246 & 29.0 \\
\hline CoalL1 & 0.88 & 16.0 & 8.3 & 36.1 & 4.04 & 159 & 23.5 \\
\hline CoalM1 & 0.89 & 17.3 & 7.3 & 36.1 & 4.08 & 171 & 15.3 \\
\hline CoalN1 & 0.90 & 29.3 & 8.2 & 31.1 & 3.48 & 153 & 11.5 \\
\hline CoalO1 & 0.94 & 25.6 & 9.8 & 30.2 & 3.52 & 142 & 10.6 \\
\hline CoalP1 & 0.96 & 34.9 & 9.5 & 28.0 & 2.67 & 19 & 7.5 \\
\hline CoalP2 & 0.93 & 30.2 & 8.8 & 28.9 & 2.76 & 51 & 8.5 \\
\hline CoalQ1 & 1.00 & 33.9 & 8.8 & 27.7 & 2.48 & 62 & 8.4 \\
\hline CoalQ2 & 1.00 & 34.9 & 8.4 & 27.8 & 2.61 & 50 & 6.3 \\
\hline CoalQ3 & 1.01 & 32.9 & 8.2 & 28.1 & 2.33 & 43 & 8.7 \\
\hline CoalR1 & 1.00 & 35.3 & 9.6 & 25.8 & 1.71 & 0 & 2.5 \\
\hline CoalR2 & 1.00 & 39.7 & 10.2 & 26.1 & 1.34 & 0 & 1.8 \\
\hline CoalS1 & 1.00 & 33.3 & 10.4 & 27.7 & 2.20 & 36 & 4.8 \\
\hline CoalT1 & 1.03 & 36.4 & 9.4 & 28.1 & 2.96 & 114 & 12.1 \\
\hline CoalU1 & 1.11 & 31.1 & 8.8 & 24.5 & 3.04 & 163 & 9.7 \\
\hline CoalV1 & 1.14 & 35.0 & 9.2 & 24.2 & 1.77 & 38 & 4.9 \\
\hline CoalW1 & 1.38 & 29.4 & 10.9 & 20.9 & 2.49 & 120 & 8.7 \\
\hline CoalX1 & 1.50 & 28.1 & 10.3 & 19.1 & 1.32 & 54 & 5.4 \\
\hline CoalY1 & 1.54 & 37.0 & 8.3 & 16.6 & 0.00 & 0 & 1.2 \\
\hline CoalZ1 & 1.60 & 20.1 & 9.2 & 17.6 & 0.70 & 33 & 3.0 \\
\hline
\end{tabular}

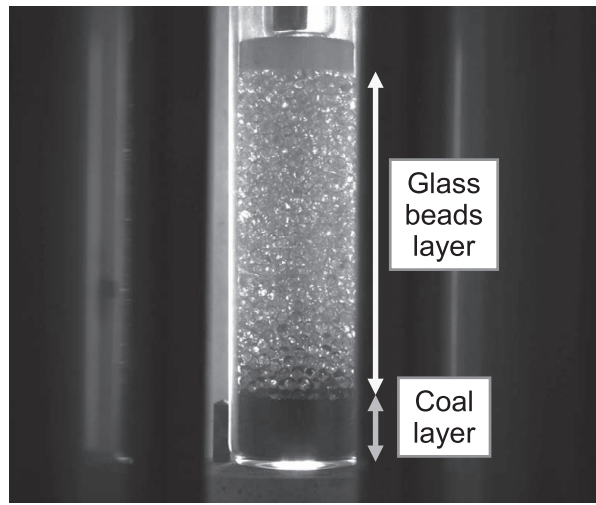

(a) Before permeation
(Boundary2) and bottom of coal layer and crucible (Boundary3) were measured by detecting the difference of brightness among the layers, filter and crucible. The difference of brightness was comparatively obvious. The coordinate of the boundary face between bottom of glass beads layer and not permeating coal layer (Boundary4) was calculated from the distance between Boundary1 and 3, and the length of glass beads layer on the assumption that the length was constant because the effect of thermal expansion was much smaller than the permeation distance. Then the permeation distance was calculated based on those coordinate values as shown in Fig. 4.

The maximum permeation distance was also estimated as below. The semicoke among the glass beads packed layer after the thermally plastic state became solidified and adhered to the glass beads. Those beads adhered to the semicoke were not able to be recovered from the crucible after cooling. On the other hand, the beads that had not adhered to the semicoke were able to be recovered. In addition, after the permeation distance reached maximum, the amount of adhered glass beads remained constant as will hereinafter be described in detail. Hence, the maximum permeation distance was derived form the beads weight and a relationship had been obtained beforehand between the packing height and the weight of the glass beads packed layer as shown in Eq. (1) below;

$$
D=H(G-M)
$$

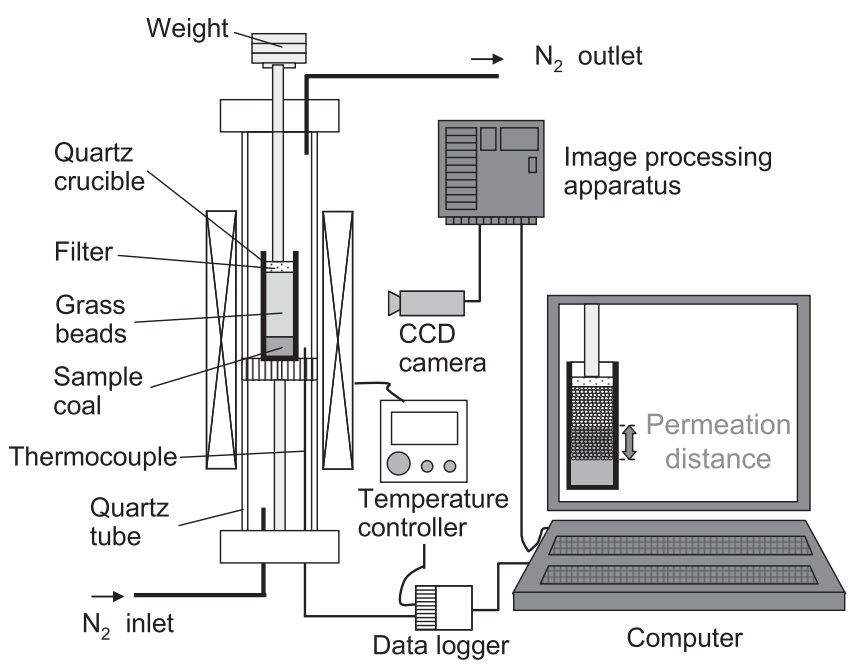

Fig. 3. Schematic diagram of measurement apparatus.

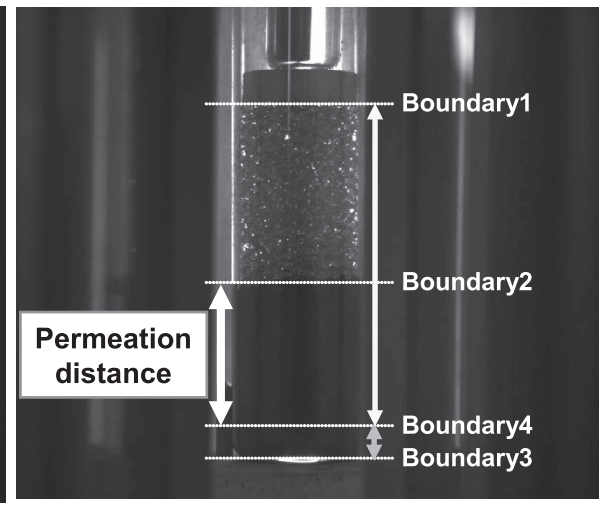

(b) After permeation

Fig. 4. Schematic illustration of coal permeation. 
where $D$ is the maximum permeation distance (mm), $H$ is the height of the packed layer per $1 \mathrm{~g}$ of the glass beads packed into this experimental crucible $(\mathrm{mm} / \mathrm{g}), G$ is the weight of the initially packed glass beads $(\mathrm{g})$ and $M$ is the weight of the beads that had not adhered together with the semicoke $(\mathrm{g})$.

\subsection{Results and Discussions}

\subsubsection{Permeation Behavior of Coal}

Figure 5 shows the profiles of the permeation distance, fluidity of Gieseler plastometer method and piston displacement of dilatometer test for CoalA1 as an example of the results. The permeation behavior was observed within around the temperature range between IST (Initial softening temperature) and MFT (Maximum fluidity temperature) or $\mathrm{T}_{2}$ and $\mathrm{T}_{3}$. Figure 6 shows the comparison of profiles of the permeation distance among coal brands. The permeation profiles were different from coal to coal. In addition, the permeation distance became constant after reaching maximum although the sample coal remained in thermally plastic state. If the permeation behavior is dominated only by viscosity, the permeation distance must change during the thermally plastic state. The results therefore indicate that the permeation behavior is dominated not only by viscosity but also by other factors.

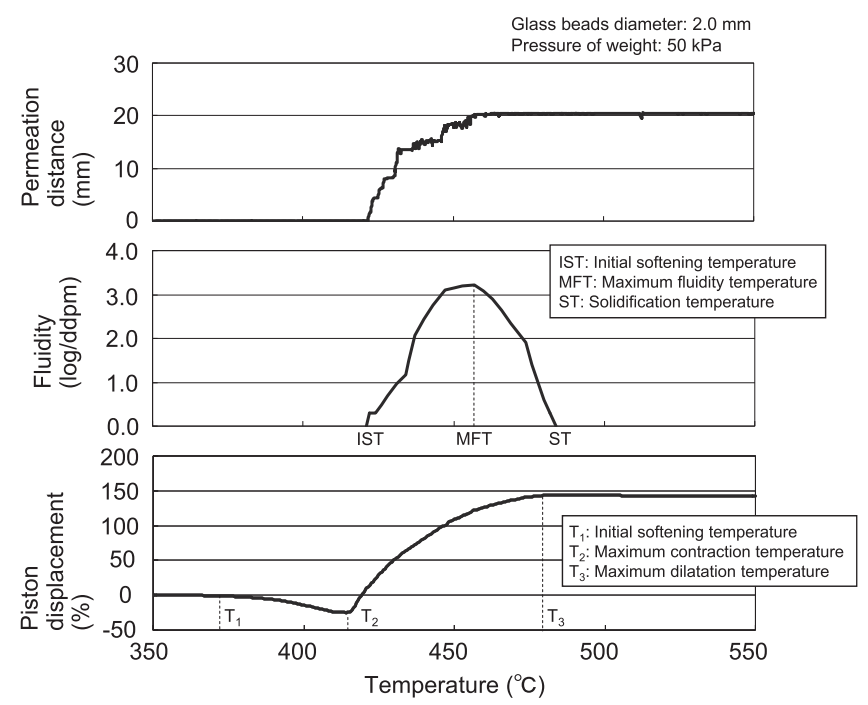

Fig. 5. Comparison of profiles between permeation distance and conventional thermoplasticity based on JIS M8801 (CoalA1).

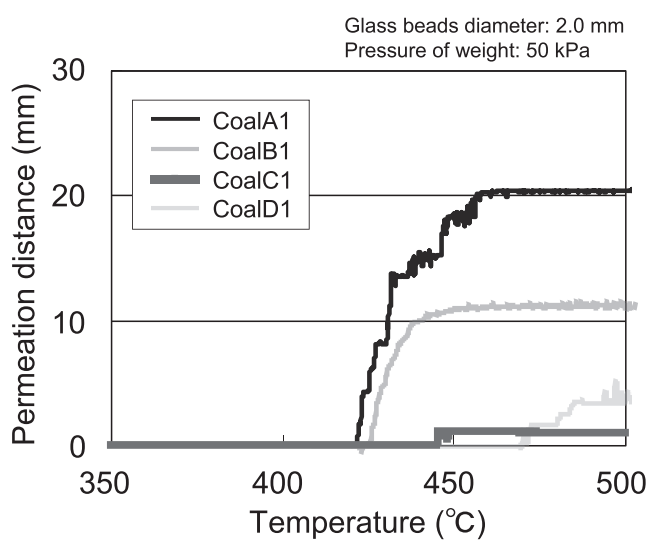

Fig. 6. Comparison of profiles of permeation distance among coal brands.
Figure 7 shows the relationship between the maximum permeation distance measured from the method by glass beads weight and by image analysis technique. Both measurement methods were reasonable for measuring the permeation distance because there was a good relationship between both measured values. More precisely, the noise of measured value because of the tar adhesion to observation window was sometimes observed in case of the method by image analysis technique. Therefore the measured values calculated by the amount of glass beads are shown as the maximum permeation distance throughout this report if not otherwise specified.

\subsubsection{Effect of Experimental Conditions on Permeation Distance}

The relationships between the maximum permeation distance and experimental conditions are shown in Fig. 8. The maximum permeation distance was increased and saturated with increasing the diameter. On the other hand, the maximum permeation distance shows an almost constant value against the weight change.

For verifying these results and clarifying the dominant factors of the permeation behavior, a fluidics approach was attempted. It is well known that the pressure drop in packed bed layer can be represented by Darcy's law as shown in Eq. (2);

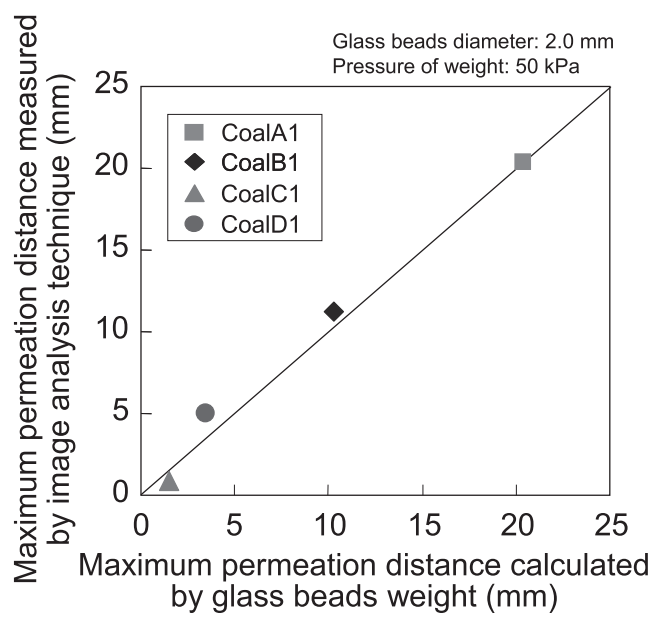

Fig. 7. Comparison between the maximum permeation distance measured from the method by glass beads weight and by image analysis technique.

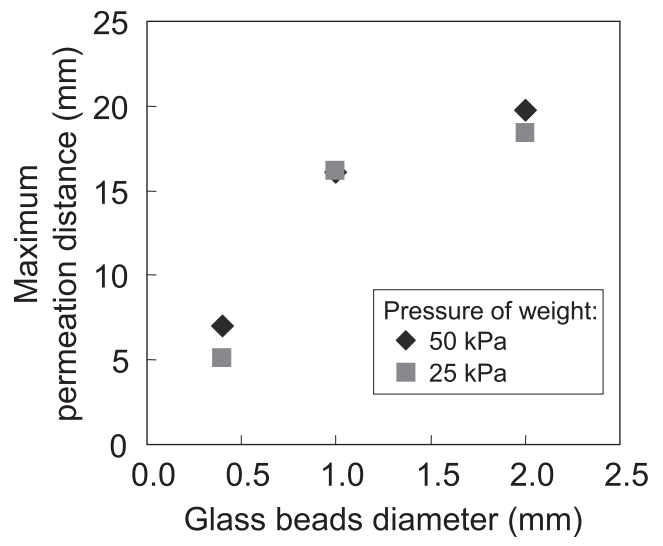

Fig. 8. Relationships between experimental conditions and maximum permeation distance (CoalA2). 


$$
\frac{\Delta P}{L}=\frac{1}{K} \mu u
$$

where $\Delta P$ is a pressure loss in the packed layer $(\mathrm{Pa}), L$ is a height of the layer $(\mathrm{m}), K$ is a permeability coefficient $\left(\mathrm{m}^{2}\right)$, $\mu$ is a viscosity of the material ( $\mathrm{Pa} \mathrm{s}$ ), and $u$ is a flow rate $(\mathrm{m} / \mathrm{s})$. Although permeation phenomenon is not exactly the same as the pressure drop in packed bed represented by Eq. (2), the following approximation was tried. It is assumed that $\Delta P$ is a coking pressure as a driving force of the permeation, $L$ is permeation distance, $K$ is determined by void structure of glass beads layer, $\mu$ is a viscosity of the thermally plastic coal, $u$ equals $L / t$ where $t$ is the time period of permeation. Then the Eq. (2) can be expressed as Eq. (3).

$$
L=\sqrt{\frac{\Delta P K t}{\mu}}
$$

According to the Eq. (3), it is estimated that $L$ is proportional to the square root of the $\Delta P$ and $K . K$ of glass beads layer is calculated by Kozeny-Carman equation; ${ }^{13}$

$$
\frac{1}{K}=k_{\mathrm{c}} S_{\mathrm{v}}{ }^{2} \frac{(1-\varepsilon)^{2}}{\varepsilon^{3}}
$$

where $k_{\mathrm{c}}$ is a Kozeny constant ( $=5.0$, in general), $S_{\mathrm{v}}$ is a specific surface area of the packed layer $\left(\mathrm{m}^{-1}\right), \varepsilon$ is a void ratio of the layer (-), respectively. When the packed bed consist of spherical material, $S_{\mathrm{v}}$ equals $6 / d$ where $d$ is a diameter of the material (m). According to the Eq. (4), the relationship between permeability coefficient of glass beads layer and glass beads diameter was derived as shown in Fig. 9. In this calculation, the measured void ratio of glass beads layer having each diameter was assigned to $\varepsilon(=0.361,0.364$, 0.387 when the diameters are $0.4,1.0,2.0 \mathrm{~mm}$, respectively). Thus, it is considered that the permeation constant is varied with change of the diameter, and that affects the maximum permeation distance as shown in Fig. 8. It is suggested that the permeation behavior under the actual cokemaking conditions could be controlled by changing coal size and permeability coefficient of the void structure of coal packed bed. On the other hand, it is indicated that the main driving force of the permeation behavior should not be the pressure of weight judging from the result in Fig. 8. It is considered that the most probable main driving force is expansion pressure of coal sample. As the evidence of above consideration,

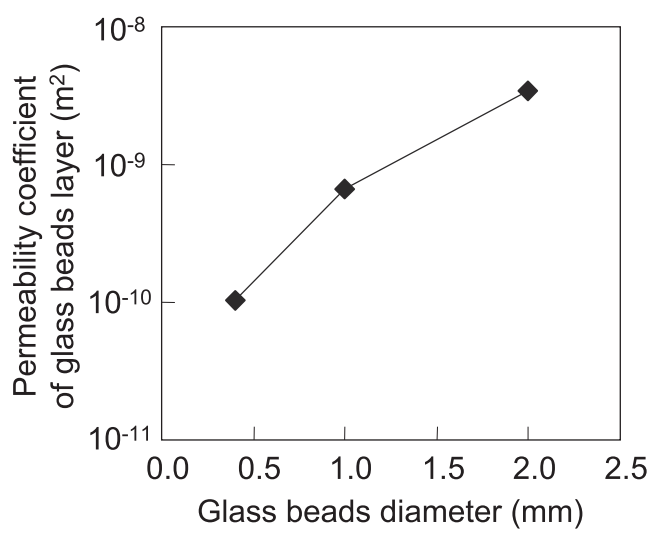

Fig. 9. Relationship between permeability coefficient of glass beads layer and glass beads diameter. the temperature range of the expansion pressure is between IST and MFT and nearly corresponds with the one of the permeation. ${ }^{14)}$ One of the dominant factors of expansion pressure is internal gas pressure. The internal gas pressure is varied with change of coal size. ${ }^{15,16)}$ Therefore the expansion pressure should be varied with change of coal size. In addition, if the expansion pressure is the main driving force of permeation behavior, it is also suggested that the permeation distance could be controlled by changing coal size.

\subsubsection{Relationship between Permeation Distance and} Conventional Coal Thermoplasticity

In the standard conditions, the measured maximum permeation distance of each coal brand is also shown in Table 1. Figure 10 shows a relationship between the maximum permeation distance and $\log \mathrm{MF}$ of each coal. The maximum permeation distance showed a certain extent of correlation with logMF, however some large deviations were observed in high fluidity coal (over around 3.0). Deviations were also observed in the relationship between the maximum permeation distance and TD as shown in Fig. 11. These results show that the maximum permeation distance is a unique parameter for representing coal thermoplasticity especially for high fluidity coal which the conventional methods cannot correctly evaluate.

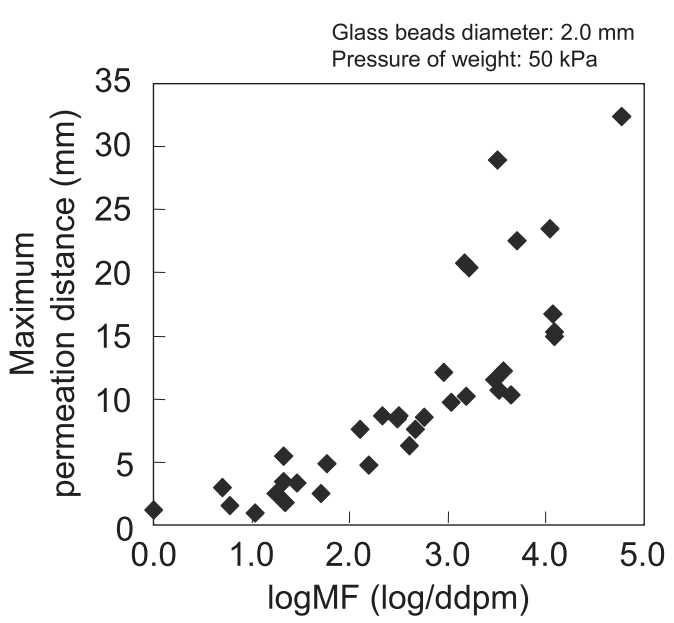

Fig. 10. Comparison between maximum permeation distance and Gieseler maximum fluidity (MF).

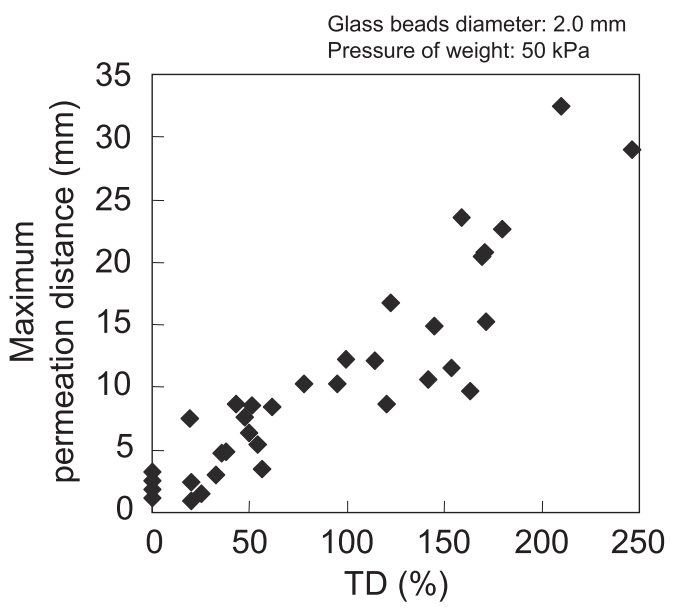

Fig. 11. Comparison between maximum permeation distance and total dilatation (TD). 


\section{Investigations of Relationship between Permeation Distance and Coke Quality}

\subsection{Experiments}

The difference in the maximum permeation distance in high MF coals shown in Fig. 10 prompted us to examine the effect of blending high MF coals whose maximum permeation distance was different on coke strength. In order to clarify the effect, carbonization tests and evaluations for obtained coke were carried out as below.

At first, the effects of the maximum permeation distance of high MF coal in coal blend on the coke strength and structure were evaluated (Test1). The detailed characterization data of the coal blends are shown in Table 2. In the Test1, CoalA2, B2 and F1 were chosen as the high MF coal. Then those high MF coal were blended so that the blending ratio in sample coal blend became $20 \mathrm{wt} \%$. The coal blends were carbonized in an electric furnace under the conditions shown in Table 3. After carbonization, the produced coke was cooled under nitrogen. The coke strength (drum Index) of the obtained coke was determined based on JIS K2151. In addition, the coke made from coal blend No.1-3 was embedded into resin and polished. Then the pictures of those samples were taken by optical microscope at 100 -fold magnification. For quantifying the pore-wall structure of the coke, the pore-wall thickness was measured by image analysis software (Nippon Roper: Image-Pro Plus version4.0) as follows. Firstly, all the shot microscopic images $(700 \times 900$ $\mu \mathrm{m})$ were binarized based on a set RGB threshold value so that the coke matrix and pore were discriminated. Secondly, the vertical lines were arranged on the every image at equal intervals $(66 \mu \mathrm{m})$. Thirdly, the coke matrix length just on the lines was measured by image analysis technique. Then the

Table 3. Carbonization test conditions.

\begin{tabular}{lcc}
\hline & Test1 & Test2 \\
\hline Coal size $(\mathrm{wt} \%)$ & $-3 \mathrm{~mm}: 100$ & $-3 \mathrm{~mm}$ or $-6 \mathrm{~mm}: 100$ \\
Moisture content $(\mathrm{wt} \%)$ & 8 & 8 \\
Bulk density $\left(\mathrm{kg}\right.$-dry $\left./ \mathrm{m}^{3}\right)$ & 750 & 750 \\
Dimensions $(\mathrm{mm})$ & $\mathrm{W} 250 \times \mathrm{H} 600 \times \mathrm{L} 413$ & $\mathrm{~W} 273 \times \mathrm{H} 300 \times \mathrm{L} 260$ \\
Wall temperature $\left({ }^{\circ} \mathrm{C}\right)$ & 1050 & 1050 \\
Coking time $(\mathrm{min})$ & 500 & 380 \\
\hline
\end{tabular}

Table 2. Coal blending conditions.

\begin{tabular}{|c|c|c|c|c|c|c|c|c|c|c|}
\hline \multirow{2}{*}{ Coal brand } & \multicolumn{3}{|c|}{ Test1 } & \multicolumn{7}{|c|}{ Test2 } \\
\hline & Blend1 & Blend2 & Blend3 & Blend4 & Blend5 & Blend6 & Blend7 & Blend8 & Blend9 & Blend 10 \\
\hline CoalF1 & 20.0 & & & & & & & & & \\
\hline CoalB2 & & 20.0 & & & & & & & 20.0 & 5.0 \\
\hline CoalA2 & & & 20.0 & & & & & & & \\
\hline CoalI1 & 12.0 & 11.0 & 19.0 & & & & & & 14.0 & \\
\hline CoalQ1 & 20.0 & 18.0 & 3.0 & & & & & & 19.0 & \\
\hline CoalR1 & 20.0 & 19.0 & 18.0 & & & & & & & \\
\hline CoalS1 & 10.0 & 8.0 & 20.0 & & & & & & 13.0 & \\
\hline CoalC2 & 6.0 & 9.0 & 9.0 & & & & & & 11.0 & \\
\hline CoalW1 & 8.0 & 10.0 & 6.0 & & & & & & 8.0 & \\
\hline CoalZ1 & 4.0 & 5.0 & 5.0 & & & & & & 4.0 & \\
\hline CoalE1 & & & & 15.0 & 10.0 & 5.0 & & & & \\
\hline CoalN1 & & & & 15.0 & 15.0 & 15.0 & & & & \\
\hline CoalP1 & & & & 20.0 & 20.0 & 20.0 & & & & \\
\hline CoalQ2 & & & & 25.0 & 25.0 & 25.0 & & & & \\
\hline CoalU1 & & & & 10.0 & 7.0 & 6.0 & & & & \\
\hline CoalC3 & & & & 15.0 & 18.0 & 19.0 & & & & \\
\hline CoalG1 & & & & & 5.0 & 10.0 & & 5.0 & & \\
\hline CoalV1 & & & & & & & & & 11.0 & \\
\hline CoalQ3 & & & & & & & 18.0 & 17.1 & & \\
\hline CoalO1 & & & & & & & 16.0 & 15.2 & & \\
\hline CoalX1 & & & & & & & 18.0 & 17.1 & & 13.0 \\
\hline CoalR2 & & & & & & & 20.0 & 19.0 & & 22.0 \\
\hline CoalP2 & & & & & & & 19.0 & 18.1 & & 30.0 \\
\hline CoalJ1 & & & & & & & 9.0 & 8.6 & & 19.0 \\
\hline CoalT1 & & & & & & & & & & 11.0 \\
\hline$\overline{\mathrm{R}} \mathrm{o}(\%)$ & 0.99 & 0.99 & 0.99 & 1.00 & 1.01 & 1.01 & 1.05 & 1.03 & 0.98 & 0.99 \\
\hline $\log \mathrm{MF}(\log / \mathrm{ddpm})$ & 2.2 & 2.2 & 2.1 & 2.8 & 2.8 & 2.8 & 2.2 & 2.3 & 2.2 & 2.2 \\
\hline Coal size & $-3 \mathrm{~mm}$ & $-3 \mathrm{~mm}$ & $-3 \mathrm{~mm}$ & $\begin{array}{l}-3 \mathrm{~mm} \text { or } \\
-6 \mathrm{~mm}\end{array}$ & $-6 \mathrm{~mm}$ & $\begin{array}{l}-3 \mathrm{~mm} \text { or } \\
-6 \mathrm{~mm}\end{array}$ & $-3 \mathrm{~mm}$ & $-3 \mathrm{~mm}$ & $-3 \mathrm{~mm}$ & $-3 \mathrm{~mm}$ \\
\hline
\end{tabular}


measured length of each image was averaged as mean porewall thickness.

Next, the effect of the blending ratio of high MF coal in coal blend on the coke strength was also evaluated (Test2). The detailed characterization data of the coal blends and the carbonization test conditions are also shown in Tables 2 and 3. In the Test2, CoalB2, E1 and G1 were chosen as the high MF coal. Blends4-8 are the levels for evaluating the effect of long permeation distance coal, CoalG1. In order to clarify the MF impact on coke strength, the mean $\log M F$ of Blends $4-6$ were set to 2.8 and the one of Blends 7,8 were set to 2.2-2.3. In more detail, the blending ratio of CoalG1 in Blends4-6 was decreased in return for increasing the ratio of CoalE1 whose maximum permeation distance was short. Blend 8 consisted of $95 \mathrm{wt} \%$ of Blend 7 and $5 \mathrm{wt} \%$ of CoalG1. Blends9, 10 are the levels for evaluating the effect of short permeation distance coal, CoalB2. After carbonization and cooled, the coke strength (drum Index) of the obtained coke was determined based on JIS K2151.

\subsection{Results and Discussions}

Figure12 shows the relationship between the maximum permeation distance of high MF coal included in coal blends (Blend1-3) and the strength of coke obtained from Test1. It clearly shows that when the longer maximum permeation distance coal is in a coal blend, the strength of the obtained coke becomes lower. Figure $\mathbf{1 3}$ shows the relationship

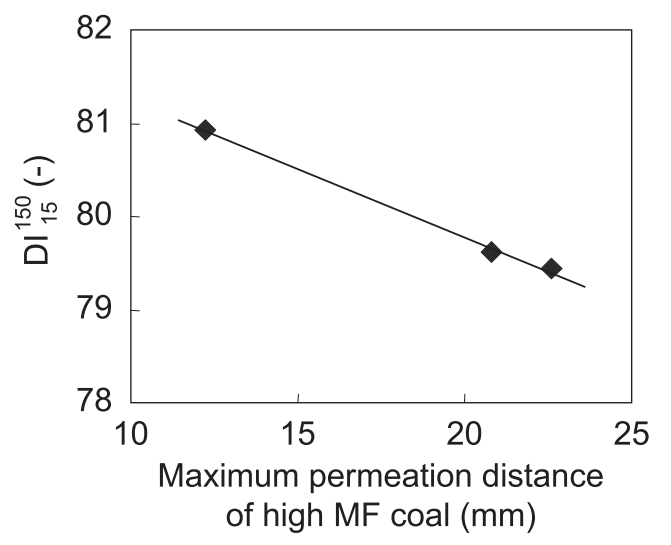

Fig. 12. Effect of maximum permeation of high MF coal on coke strength (Blend1-3).

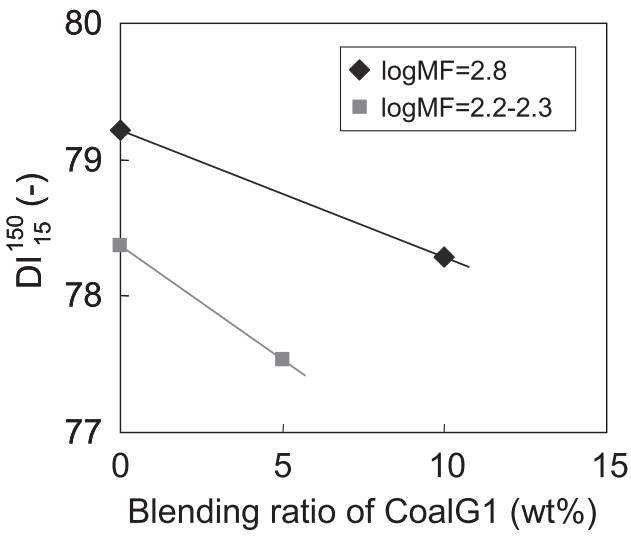

(a) between the blending ratio of the high MF coal brand (CoalB2 or CoalG1) and the coke strength. It was observed that coke strength decreased with increasing CoalG1 in coal blend though averaged $\log \mathrm{MF}$ levels of coal blend was changed from 2.2 to 2.8 . On the other hand, the coke strength did not decrease when the blending ratio of the short maximum permeation distance coal (CoalB2) was increased. These results suggest that the cause of deterioration of coke strength is the long maximum permeation distance coal itself.

Figure 14 shows the effect of size of coal blend on coke strength. The coke strength was more drastically decreased with increasing CoalG1 in case coal size was bigger. In general, it is well known that size of high caking property coal should be kept larger for making high strength coke because caking property is decreased with decreasing coal size. ${ }^{17)}$ However as shown in Fig. 14, it is suggested that the strength of coke produced from coal blend including the long permeation distance coal could be maintained by more pulverizing the coal blend.

Figure 15 shows optical microscopic images of the coal Blend1 and 2. It was observed that the thickness of the porewall of coke derived from Blendl including the long maximum permeation distance coal (CoalF1) was thinner than photo(b) where the short maximum permeation distance CoalB2 was blended. The relationship between the mea-

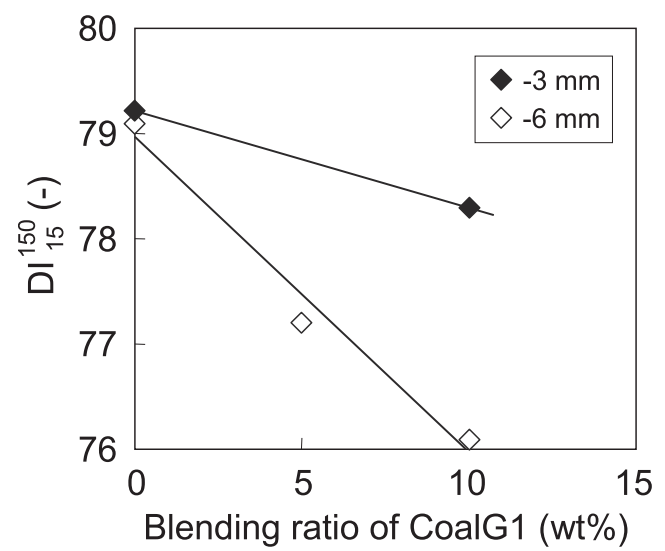

Fig. 14. Effect of size of coal blend on coke strength with increasing amount of long maximum permeation distance coal (Blend4-6).

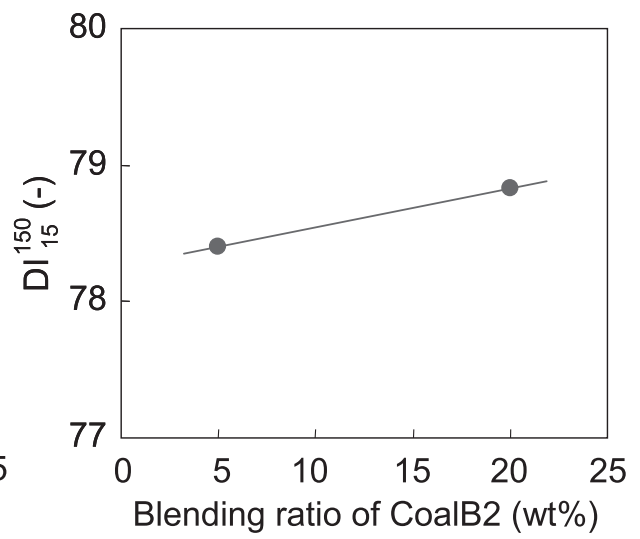

(b)

Fig. 13. Relationship between blending ratio of high MF coal and coke strength ((a) Long maximum permeation distance coal: CoalG1 (Blend4, 6-8), (b) Short maximum permeation distance coal: CoalB2 (Blend9, 10)). 
sured mean pore-wall thickness and the maximum permeation distance of high MF coal is shown in Fig. 16. This relationship strongly suggests that the long maximum permeation distance coal produces the coke structure having thinner wall and produces weaker coke structure as a result.

The presumed behavior of high MF coal with thermally plastic state is shown in Fig. 17. In Fig. 17(a), the long maximum permeation distance coal permeates into gaps between packed particles or void upon heating. After per-

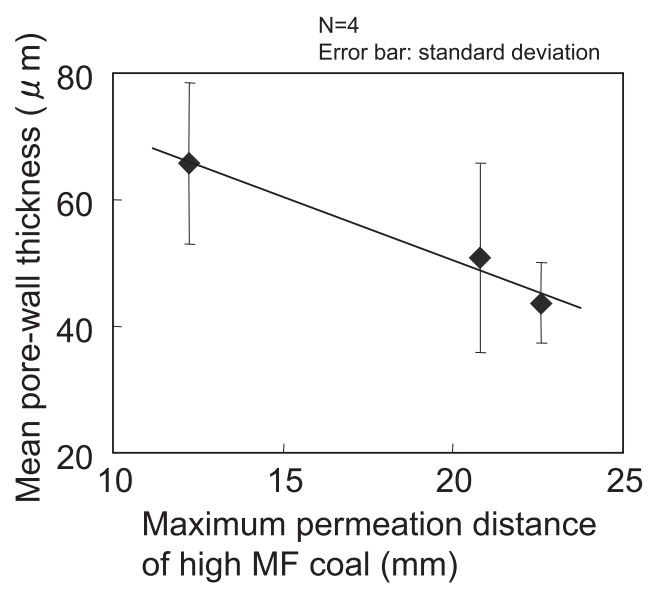

Fig. 16. Effect of the maximum permeation of high MF coal on mean pore-wall thickness (Blend1-3). meation is completed, thin pore-walls are formed and large pores are left in places in which the particles have been originally present, which result in the decrease in the coke strength. On the other hand, Fig. 17(b) shows the structure formed from coal blend including the short maximum permeation distance coal. The coal permeates into the void less than the long maximum permeation distance coal does. Consequently, thick pore-walls are formed and no large pore is left. According to the previous studies about relationship between coke strength and coke structure, it was reported that large pores especially having the mm-scale diameter behave as the defects of coke and decrease the coke strength. $^{18-20)}$ It was also reported that coke strength is decreasing as the pore-wall thickness becomes thin. ${ }^{21)}$ Therefore it is considered that the difference of void left after permeation and pore-wall thickness are critical for understanding the difference of the effect of the long maximum permeation coal and the short maximum permeation coal on coke strength. Based on these results, the cause of coke strength decrease in excessively high MF coal blend is suggested to be the existence of the long maximum permeation distance coal in a coal blend. Furthermore it is proposed that the permeation distance can supplement the Gieseler fluidity as the caking property especially for evaluating high fluidity coal and contribute to improving the anticipation of coke strength, namely blending technique.
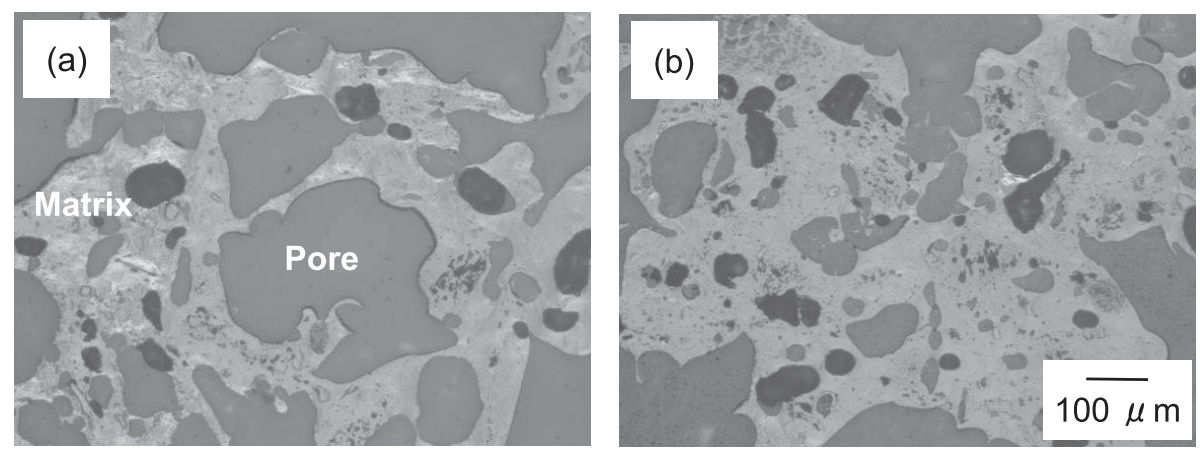

Fig. 15. Polarizing microscope images of coke structure ((a) Blend1, (b) Blend2).

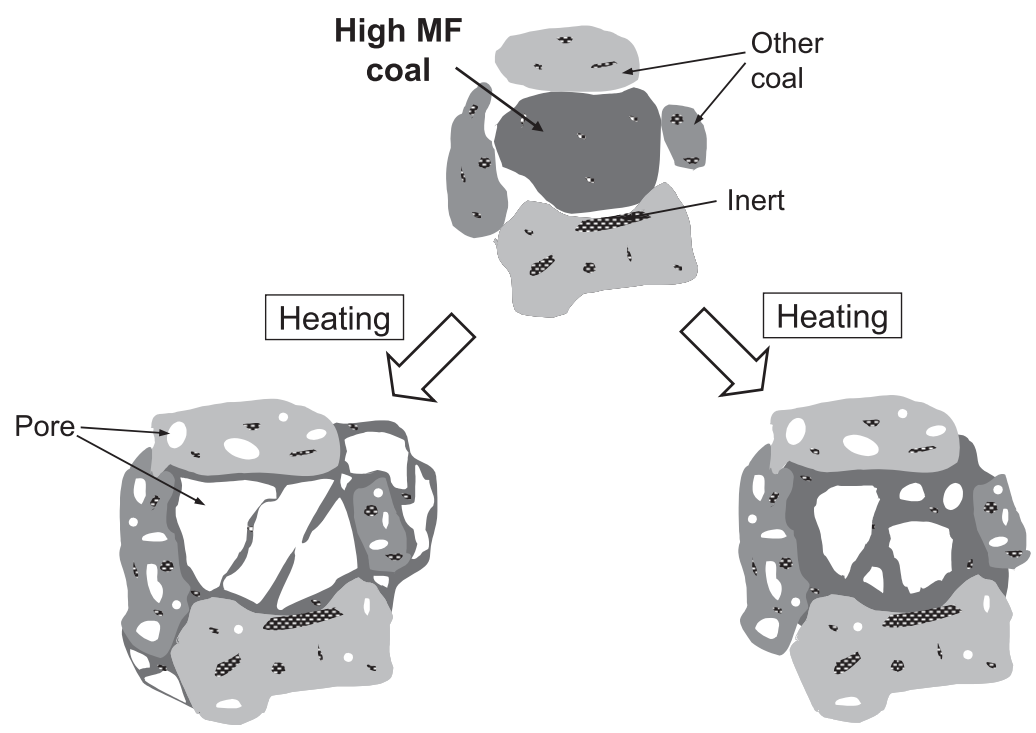

(a) Long maximum permeation distance coal

(b) Short maximum permeation distance coal

Fig. 17. Schematic illustration of behavior of long and short maximum permeation distance coal. 


\section{Applications of Permeation Distance to Commercial Plant}

\subsection{Experiments}

For verifying the commercial-scale impact of the permeation distance on coke strength, a plant trial was implemented at Keihin No.1 coke oven battery (124 chambers, W0.45 $\times$ $\mathrm{H} 7.55 \times \mathrm{L} 17.0 \mathrm{~m})$. The working rate was $125 \%$ during the trial. The blending ratio of the long maximum permeation distance CoalA2 in commercial coal blend was decreased in return for increasing the ratio of the short maximum permeation distance CoalH1. Then the variation of coke strength was evaluated. During the trial, average $\bar{R}$ o and $\log \mathrm{MF}$ of coal blend were kept constant.

\subsection{Results and Discussions}

Figure 18 shows the variations of coke strength, $\bar{R} 0$, $\log \mathrm{MF}$ and blending ratio of CoalA2 and CoalH1. With replacing CoalA2 to CoalH1, the coke strength enhanced. Averaged coke strength while the blending ratio of CoalA2 was more than $10 \mathrm{wt} \%$ (1-9 day) was 84.3 . On the other hand, averaged coke strength while the ratio was not more than $10 \mathrm{wt} \%$ (10-16 day) was 84.7. The difference was statistically-meaningful in consequence of two-sample t-test under the conditions that the two-sided 95\% confidence interval was used and the dispersion of each level was assumed same. Therefore it is clarified that the permeation distance is effective and important as the caking property because it indeed affects on the coke strength under the conditions of commercial operations. By employing the permeation distance method, contribution to the production of high strength coke and effective usage of caking coal will be expected.
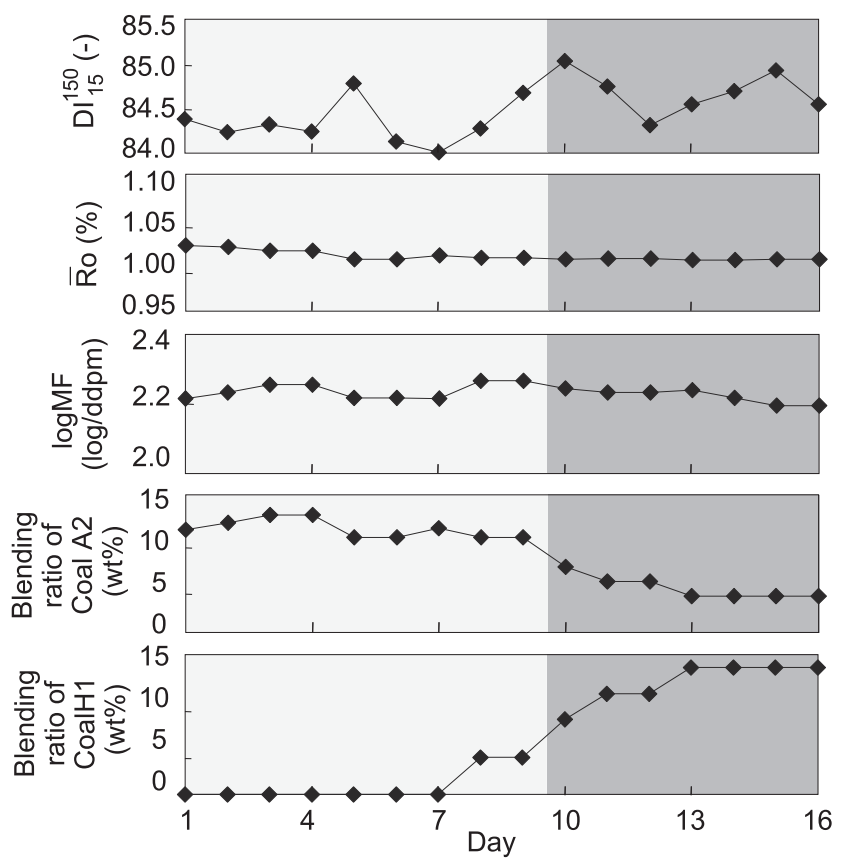

Fig. 18. Variations of coke strength with changing the blending ratio of long and short maximum permeation distance coal at commercial plant.

\section{Conclusions}

A novel method for evaluating coal thermoplasticity is developed. The method includes measuring the permeation distance of thermally plastic coal into glass beads layer placed adjacent to the coal sample. Following findings and implications were obtained in terms of the permeation distance;

(1) Rough correlations between the maximum permeation distance and conventional coal thermoplasticity (Gieseler maximum fluidity (MF) and total dilatation (TD)) were observed, however large deviation from the correlation was observed especially in higher MF coals. Permeation distance measurement is an improved method especially for evaluating thermoplasticity of high MF coal and can supplement the Gieseler Fluidity by overcoming idling of stirring rod.

(2) Coal that has the long maximum permeation distance forms large pore and thinner pore-wall structure in coke, which induces deterioration of coke strength when the coal blend includes the long maximum permeation distance coals.

(3) The coke strength deterioration caused by the long maximum permeation distance coals was reduced as the grain size of coal blend becomes smaller.

(4) The difference of the maximum permeation distance in high MF coals rationalizes the decrease of coke strength in case that high MF coal is used in a coal blend.

(5) By employing the permeation distance method, more precise evaluation of coal thermoplasticity is realized, which enables us more effective usage of coal resources and to produce high strength coke.

\section{REFERENCES}

1) H. Joh: J. Fuel Soc. Jpn., 26 (1947), 1.

2) N. Schapiro and R. J. Gray: J. Inst. Fuel, 37 (1964), 234

3) Y. Miura, T. Okuhara, T. Nishi, T. Yamaguchi and H. Haraguchi: Trans. Iron Steel Inst. Jpn., 21 (1981), 518.

4) Y. Miura, T. Okuhara, T. Nishi, T. Yamaguchi and H. Haraguchi: Trans. Iron Steel Inst. Jpn., 21 (1981), 518.

5) T. Miyazu, Y. Okuyama, Y. Suzuki, T. Fukuyama and T. Mori: NKK Tech. Rep., 67 (1975), 125.

6) S. Nomura, T. Arima and K. Kato: Fuel, 83 (2004), 1771.

7) M. Uchida, Y. Kubota, T. Nakagawa and S. Nomura: Proc. of 21st Annual Meeting of the Jpn. Inst. Energy, Japan Institute of Energy, Tokyo, (2012), 34

8) H. Morotomi, N. Suzuki, T. Miyazu and M. Simura: J. Fuel Soc. Jpn., 53 (1974), 779.

9) S. Nomura, K. Kato, I. Komaki, Y. Fujioka, K. Saito and I. Yamaoka: J. Jpn. Inst. Energ., 78 (1999), 33.

10) Y. Sunami, K. Nishioka, M. Ogawa and S. Yoshida: Tetsu-toHagané, 67 (1981), S107.

11) N. Suzuki and S. Itagaki: Tetsu-to-Hagané, 72 (1986), S29.

12) R. Loison, P. Foch and A. Boyer: Coke, Butterworths, England, (1989), 398.

13) P. C. Carman: Trans. Inst. Chem. Eng., 15 (1937), 150.

14) K. Nishioka and S. Yoshida: J. Fuel Soc. Jpn., 68 (1988), 210.

15) T. Arima and K. Kato: CAMP-ISIJ, 15 (2002), 176.

16) S. Nomura, T. Arima, A. Dobashi and K. Doi: ISIJ Int., 51 (2011), 1425.

17) E. Burstlein: Glïckauf, 92 (1956), 606.

18) T. Arima: Tetsu-to-Hagané, 87 (2001), 274.

19) M. Sakai, R. Nishimura, M. Nishimura and K. Fukuda: Tetsu-toHagané, 92 (2006), 164.

20) K. Ueoka, T. Ogata, Y. Matsushita, H. Aoki, T. Miura, K. Fukuda and K. Matsudaira: Tetsu-to-Hagané, 93 (2007), 728.

21) M. Nishimura, K. Matsudaira and S. Asada: Tetsu-to-Hagané, 82 (1996), 431. 